\title{
Drospirenone/Ethinyl Estradiol
}

National Cancer Institute

\section{Source}

National Cancer Institute. Drospirenone/Ethinyl Estradiol. NCI Thesaurus. Code C106205.

A combination of two steroid sex hormones, the estrogen ethinyl estradiol and a progestin drospirenone, used for contraceptive purposes. The combination of ethinyl estradiol with drospirenone suppresses the hypothalamic-pituitary system, leading to an inhibition of the release of gonadotropin hormones follicle stimulating hormone (FSH) and luteinizing hormone (LH). The inhibition of FSH release suppresses the development of ovarian follicle. The decreased release of LH inhibits ovulation. In addition, thickening of the cervical mucus and the endometrium is promoted, thereby altering the endometrium in such a way as to discourage implantation. 